\title{
Correction to: Life Cycle Assessment of a Hydrogen and Fuel Cell RoPax Ferry Prototype
}

Juan Camilo Gomez Trillos, Dennis Wilken, Urte Brand, and Thomas Vogt

\section{Correction to:}

Chapter 2 in: S. Albrecht et al. (eds.), Progress in Life Cycle Assessment 2019, Sustainable Production, Life Cycle Engineering and Management, https://doi.org/10.1007/978-3-030-50519-6_2

In the original version of the book, the legend of the Fig. 2.2 was corrected. The chapter and book have been updated with the changes. 


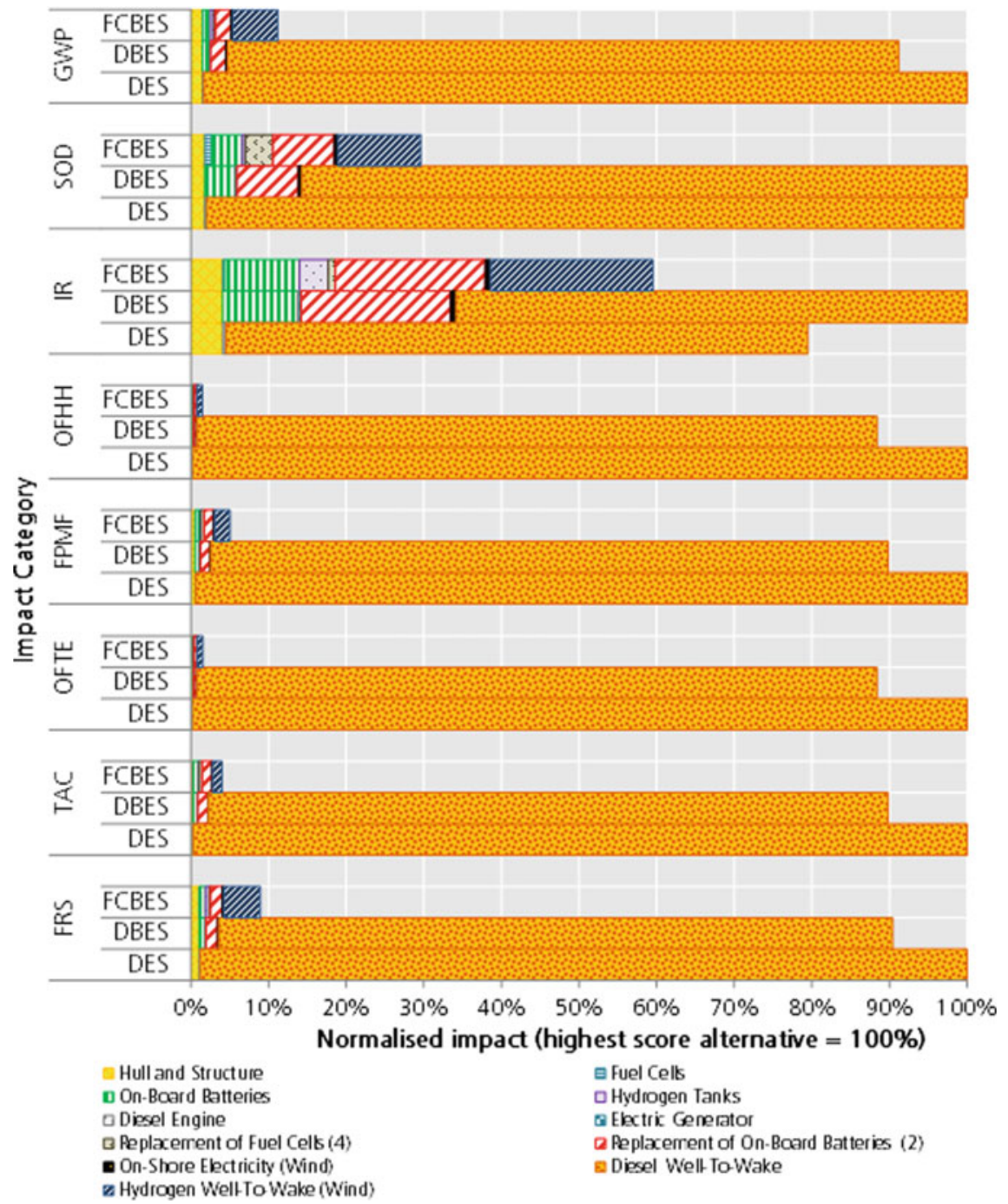

Fig. 2.2 Comparison of the midpoint impact assessment results for diesel electric ship (DES), diesel battery electric ship (DBES) and fuel cell battery electric ship (FCBES) RoPax ferry alternatives in the categories in which the FCBES has lower impact. Results normalised to the highest total impact alternative in each of the categories 